\title{
EM TERRAS POTIGUARAS, CORPO E CULTURA INDÍGENA NO CONTEXTO CATU
}

Recebido em: 06/10/2021

Aprovado em: 11/11/2021

Licença: @) (1) @

Carlos Gomes de Medeiros Neto

Rede Estadual de Educação (SEEC/RN)

Natal - RN - Brasil

José Pereira de Melo

Universidade Federal do Rio Grande do Norte (UFRN)

Natal - RN - Brasil

Marta Genú Soares

Universidade do Estado do Pará (UEPA)

Belém - PA - Brasil

RESUMO: Existem na Comunidade do Catu saberes, vivências e práticas culturais tradicionais que resistem e são ressignificadas pelos povos potiguaras do lugar. O estudo objetiva mapear as práticas corporais para perceber os saberes que as significam como identidade da Comunidade dos Indígenas do Catu. Usa o referencial dos estudos culturais e da abordagem etnográfica e adota o diário de campo e a iconografia que resultam no desenho prático-teórico da organização dos Catu. Conclui sobre a necessidade educativa de se assumir a co-responsabilidade diante do desafio de construir novos caminhos para a Educação Indígena Potiguar.

PALAVRAS-CHAVE: Relações étnico-raciais. Educação indígena. Corpo e cultura.

\section{IN POTIGUARA LAND, BODY AND INDIGENOUS CULTURE IN THE CATU CONTEXT}

ABSTRACT: The Catu Community has traditional cultural knowledge, experiences and practices that resist and are re-signified by the local people. The study aims to map corporal practices to perceive the knowledge that signifies them as the identity of the Catu Indigenous Community. It uses cultural studies as a reference and the ethnographic approach. It adopts the field diary and iconography that result in the practical-theoretical design of the organization of the Catu Community. It concludes there's the educational need to assume co-responsibility in the face of the challenge of creating new paths for the Potiguar Indigenous Education.

KEYWORDS: Ethnic-racial relations. Indigenous education. Body and culture. 


\section{Texto Inicial e Contexto Local}

Este estudo ${ }^{1}$ trata das informações obtidas a partir de uma etnografia realizada em comunidade indígena, na escola e nos espaços e equipamentos ressignificados e utilizado para as práticas corporais. Como recorte temporal de uma pesquisa de dois anos, essa escrita se desenvolve conhecendo os caminhos da Comunidade. Os caminhos, informações e os dados que foram reunidos e que possibilitaram compreender a Comunidade Indígena do Catu, na Cidade de Canguaretama/RN.

No apanhado aqui relatado objetivamos mapear os saberes que dão sentido e significado às práticas corporais, já caracterizadas como migrações culturais que transitam entre o passado e o presente, entre os indígenas e os não indígenas, entre as identidades que se cruzam na Comunidade do Catu. No decorrer metodológico a abordagem etnográfica cerca a convivência e a experiência construída e registada no diário de campo e nas imagens fotográficas.

Para acesso a Comunidade do Catu, como ponto de partida/inicial, elegemos as Cidades de Natal (ponto inicial) e a de Canguaretama/RN ( localização dos Catu). Nesse sentido, foi feita a escolha da Cidade de Natal como ponto de partida, por ser a capital do Estado do Rio Grande do Norte. O trajeto, inicial e final, delimita-se com referência na BR-101, isso para um bom acesso. Como localizador, na Cidade de Canguaretama, pode-se seguir até a Subestação de energia elétrica, esse foi o melhor acesso quando estivemos próximos à Cidade de Canguaretama. Depois, procuramos seguir pela marginal da pista, sendo o Instituto Federal de Educação, Ciência e Tecnologia do Rio Grande do Norte (IFRN), Campus Canguaretama outra referência. Na saída de Natal até Canguaretama seguimos no sentido da BR-RN até Canguaretama/RN. Para o acesso a Comunidade, o caminho é pela marginal após o

\footnotetext{
${ }^{1} \mathrm{O}$ estudo é interface da Dissertação de Mestrado intitulada Saberes indígenas, cultura de movimento e interculturalidade: cenários na Comunidade do Catu/RN, defendida em 2019 por Carlos Gomes de Medeiros Neto na Universidade Federal do Rio Grande do Norte.
} 
IFRN, na subestação, irá seguir à direita por estrada de terra por uma média de 06 km até o Sítio Catu/RN, onde moram e resistem os Povos Potiguara do Catu dos Eleotérios.

Essa Região Sul do Rio Grande do Norte (RN) tem sido, historicamente, reconhecida como lócus de antigos aldeamentos indígenas. Onde os habitantes viviam as margens do Rio Catu, divisa entre os Municípios de Goianinha e Canguaretama. A palavra Catu na língua Tupi significa "bom”, "bonito".

No tempo histórico, ressalta-se a relação dos povos indígenas com o massacre ocorrido em Cunhaú e Uruacú. Na ocasião, destaca-se no discurso de Vandregercíio Arcanjo da Silva, líder comunitário e morador da Comunidade, sendo conhecido no Catu por Vando, que houve o interesse em buscar e reconhecer a realidade étnica onde estava inserido, iniciando a busca da afirmação étnica da Comunidade. Vando conta, que junto com Nascimento, no ano de 2002, viajou para a Baía da Traição/Paraíba, para estabelecer contatos com os índigenas da etnia Potiguara.

Nesse período, os Eleotérios foram apresentados como uma comunidade de remanescentes indígenas do RN. Essa viagem foi conduzida por um militante da questão indígena, funcionário da Fundação José Augusto (FJA) instituição responsável pela política cultural do Estado. Assim, seriam os Potiguara os responsáveis pela afirmação étnica da Comunidade do Eleotérios no Sítio Catu/RN, isso porque, consideramos que há o fenômeno da etnogênese ou reetinização em que os "povos indígenas que, por pressões políticas, econômicas e religiosas ou por terem sido despojados de suas terras e estigmatizados em função dos seus costumes tradicionais, foram forçados a esconder e a negar suas identidades tribais como estratégia de sobrevivência" (LUCIANO, 2006, p. 28), e dessa forma, amenizam os ataques de preconceito e discriminação. 
Esse fenômeno foi percebido entre os Eleotérios e os Potiguara de Baía da Traição. Nessa trilha de significados, sentidos e reconhecimento, o Projeto Integrado de Desenvolvimento Sustentável do Rio Grande do Norte, denominado RN Sustentável (2013), traz o marco conceitual dos povos indígenas do Rio Grande do Norte. Nesse contexto, se insere a Comunidade pesquisada, os Eleotérios do Catu. Os Eleotérios, se organizam com a lógica familiar, os Simião, os Canários e os Serafim. Vivem na microrregião litorânea sul do Estado do Rio grande do Norte. Distando uma média de 79 quilômetros de Natal e a menos de 10 em relação às cidades sedes.

Diante disto, a Comunidade atualmente enfrenta vários problemas por causa dos agrotóxicos usados na margem do Rio Catu, problemas alérgicos e de saúde coletiva. Os moradores do Catu afirmam que a produção agrícola familiar está sendo afetada, pois, o Rio Catu está poluído pela Usina Canavieira.

O tamanho territorial da Comunidade Catu-Canguaretama é de 70 léguas e uma população de 122 famílias com aproximadamente 364 habitantes (RN SUSTENTÁVEL, 2013). O Catu está situado entre o limite (margens do Rio Catu) dos Municípios de Goianinha e Canguaretama, onde vivem cerca de 840 pessoas nas duas cidades. Em termos de atividade econômica, o modelo da monocultura da cana-deaçúcar, é praticado há dois séculos. Os moradores de Catu (cidadãos de direitos) são beneficiados com alguns dos programas de assistência social do governo federal, estadual e municipal, tais como: Bolsa Família, Programa Estadual do Leite, Educação de Jovens e Adultos (EJA), dentre outros. Os dados do Projeto RN Sustentável (2013) indicam que com os programas se tem a única renda de caráter continuado, além das aposentadorias.

De acordo com alguns parentes, os Eleotérios se dizem predominantemente católicos, embora exista na Comunidade pessoas praticantes de outras religiões. 
Como também foram identificados em cada um dos distritos a a existência de uma Escola Municipal Indígena.

Um dado importante e que chama nossa atenção é a contribuição e participação das mulheres nas atividades agrícolas e também na comercialização dos produtos nas feiras locais e produção de artesanato, como foi evidenciado na Feira Brasil mostra Brasil, exposição realizada no Centro de Convenções, na Cidade de Natal no ano de 2016. Onde são expostas suas obras (artesanatos, adornos e adereços) que representam e simbolizam a cultura da Comunidade.

Outro olhar instigante são as unidades produtivas que estão localizadas ao longo do Rio Catu. São diversas faixas, muito bem organizadas, com plantação de hortaliças e legumes cultivados em pequenas unidades de produção familiar. $\mathrm{O}$ manejo com a culinária é percebido na produção de alimentos como o beiju, comercializados em feiras da região agreste e que preserva uma dinâmica peculiar na sua produção.

Percebemos no cotidiano, famílias envolvidas com uma atividade peculiar, senhoras realizando pequenos cortes em mandiocas, após os cortes toda matéria prima (mandiocas) foram armazenadas em sacos grandes, por 03 dias, imersos dentro do rio. Todo esse processo de beneficiamento na intenção que a massa amoleça, ao ponto de preparar inicialmente toda a produção do alimento, conhecido na Comunidade por Beiju. Essa peculiaridade merece ser preservada e para isso o território deve ser cuidado.

Vale ressaltar que as atividades são desenvolvidads em família e que essa prática é de trabalho, com o caráter do lazer e da convivência entre as diferentes faixas etárias. Como admitimos que o lazer tem sua essência na tríade trabalho, entretenimento e desenvolvimento, constatamos que esse é o espírito imanente nas 
técnicas corporais da Comunidade quer sejam de subsistência ou de organização para as ações cotidianas.

\section{Trilhas para a Cultura Catu}

Nas aproximações entre o sujeito pesquisador e a Comunidade fomos recebidosinúmeras vezes na residência de indígenas, laço criado no ano de 2012 após a realização de um passeio ciclístico até a Comunidade. Nesse mesmo dia, conhecendo as terras do Catu, vimos moradores conversando próximo a Igreja Catu/Goianinha, nas imediações das árvores perto do rio, e nos inquietamos em saber mais sobre aquela localidade.

Aos moradores perguntamos pelas lideranças da Comunidade. Onde prontamente orientaram a procurar por Valda ou Vando, seu irmão. Fomos muito bem recepcionados por ela e seus familiares, no mesmo dia após conversas nos foi oferecido um tradicional café com tapioca, onde prolongamos nossos diálogos. Essa interação foi rica e prazerosa, pois, evidenciou seu envolvimento com as demandas dos povos indígenas e principalmente com os povos da Comunidade do Catu.

No final do ano de 2013, em um evento promovido pela Secretaria de Educação de Goianinha, intitulado Semana Pedagógica 2014, ocorreu o reencontro com Valda, onde soubemos que a mesma exercia o cargo de professora pedagoga no Município, esse envolvimento profissional e social possibilitou teias e raízes para inserção na Comunidade do Catu, onde por meio dos seus relatos mostrou-nos as potencialidades do uso do corpo na Comunidade. Surgindo assim, a primeira fonte do conhecer e aprender com os saberes do Catu.

O início da trajetória no contexto da pesquisa ocorreu em 2016 com a imersão na Comunidade nos limites geográficos do Catu/Canguaretama e também no 
Catu/Goianinha. Nas conversas informais com os moradores foram citadas algumas potencialidades para a pesquisa, a saber: Trilha do Catu; Futevôlei e o Ritual do Toré. Todo o envolvimento nas vivências da cultura dessa Comunidade nos permitiu identificar o forte apelo social com a Trilha do Catu, o futevôlei e o Ritual indígena do Toré.

A cultura Catu é vivenciada no sentido lato do conceito cultura em que as tarefas de trabalho do dia a dia significam também o divertimento pelo prazer do sentido à sobrevivência da Comunidade, e dessa forma o coletivo promove desenvolvimento individual em atividades de grupo e de manutenção da estrutura e organização local. O lazer se funde nas práticas corporais, nos jogos, nas brincadeiras e nos rituais. O sentido lúdico é vivaz e presenta nas ações que se constituem educativas.

A oralidade se fez presente entre os participantes da pesquisa e nas conversas informais sobre o Ritual do Toré na Comunidade. "Quando acontece aqui no Catu”? "Quando está no período de lua cheia". "Onde acontece"? "Na mata, ou na arena de areia". Os relatos dos moradores garantem a utilização do Ritual do Toré em períodos destinados aos festejos. Mas, não foi identificada essa prática no momento em que estivemos imersos nesse cenário.

Para a Comunidade do Catu, os povos indígenas que restaram foram estigmatizados e, por muito tempo, se esconderam sob a condição de caboclo, principalmente, lugares de refúgio como quilombos. Esse cenário, juntamente com as opressões culturais do período, e posteriormente a expulsão dos holandeses, na segunda metade do século XVII, deu-se início à conquista do interior do Nordeste e se instalou a "Guerra dos Bárbaros", uma série de ações armadas contra indígenas podem ter afetadovárias de suas dinâmicas culturais, inclusive o Ritual do Toré. 
O Ritual do Toré é manifestação da cultura em linguagem corporal e representa várias comunidades indígenas do Nordeste brasileiro. Encontram-se Torés em alguns estados dessa região como por exemplo, na Bahia, entre os Kariri, Pataxó e Tumbalalá; em Alagoas, entre os Kariri-xokó, Kalankó; e em Pernambuco, Ceará e Paraíba, entre os Pankarau e Xukuru. Para esses grupos, o Toré está relacionado ao desejo de retomar as tradições antigas para garantir a sua identidade e demarcação dos seus territórios.

No quadro a seguir, apresentamos os significados e representações comentados, dialogados e ressignificados na Comunidade Indígena do Catu.

Quadro 01: Vivências que migram no discurso e na prática da Comunidade

\begin{tabular}{|c|c|c|}
\hline Manifestação cultural & Local e Materiais & Vivência \\
\hline Trilha do Catu & $\begin{array}{c}\text { Área de proteção ambiental ao longo do } \\
\text { Rio Catu/Goianinha e Canguaretama }\end{array}$ & $\begin{array}{c}10 \mathrm{~km} \text { de trilha } \\
\text { sinalizada }\end{array}$ \\
\hline Ritual do Toré & Mata do Catu e na escola a noite & $\begin{array}{c}\text { Ritual sagrado com } \\
\text { inserção da Jurema em } \\
\text { período de lua cheia }\end{array}$ \\
Futvôlei & $\begin{array}{c}\text { Caixa de areia ao lado da escola indígena } \\
\text { no Catu/Canguaretama }\end{array}$ & $\begin{array}{c}\text { Jogam todos os dias e } \\
\text { em eventos no dia 19 de } \\
\text { abril (Dia do índio) e 01 } \\
\text { de Novembro (dia da } \\
\text { Batata) }\end{array}$ \\
\hline
\end{tabular}

Fonte: Dados de Campo, 2016.

O contexto de práticas e fenômenos existe na relação e adesão indígena com as linguagens corporal nas manifestações culturais. Todas essas práticas migram para o contexto da escola indígena. A reflexão sobre as práticas dos indígenas nos convida a permear pela cultura em seu caráter dinâmico. Ressalvando que esse processo cultural é vivo e na dinâmica ele se modifica e se atualiza permanentemente. 


\section{A Trilha no Catu: Corpo em Movimento}

Como ponto de partida no conhecer da Comunidade adentramos na realidade a partir da trilha do Catu. A trilha constitui uma vivência na natureza, um conhecimento local, uma verdadeira imersão cultural, nos quais observam-se outras respostas motoras, sensoriais e afetivas nesse espaço. Na relação cultura, vivência e prática corporal, o lazer é o espaço que se materializa como apropriação de conhecimento que contribui para o desenvolvimento da Comunidade e agrega para a escola indígena outros conhecimentos construídos na trilha.

A natureza é própria para práticas culturais que expressam a vida Catu imersa de manifestações de lazer, como fenômeno dialético que é processo e produto (MATOS, 2001), as vivências do lazer estão contraditoriamente articuladas ao trabalho, e que imbricados, assume configuração diferenciada no tempo do teritório Catu.

Este se apresenta em uma área de Mata Atlântica localizada nas Cidadesde Canguaretama e Goianinha, porém no trecho inicial da trilha as vivências para o roteiro a percorrer começam na parte Catu de Cima (Goianinha) sendo cenário propício para atividades físicas e de caça para os moradores e de lazer para os visitantes.

Ao adentramos com mais afinco na Comunidade fomos convidados a participar de uma trilha com os familiares do indígena Luiz Katu ou Luiz de Chão. Marcamos o início da trilha para às 13:00 na casa do seu pai, conhecido por Chão na Comunidade, residente na parte do Catu/Canguaretama próximo as margens do Rio Catu. Fiz minha chegada no local marcado às 12:10, fomos recebidos na residência por Ladislau, neto de Chão e filho de Luiz. Onde conhecemos parte da família, filhos, irmãos, netos e esposas. 
A família tem suas ocupações profissionais predominantemente na agricultura. Alguns dos filhos de Chão, no momento da trilha não puderam participar devido a colheita do feijão verde. Pessoas atenciosas e de grande sabedoria popular. No discurso do morador Chão, "quando era criança plantava e caçava aqui mesmo, no era preciso ir na rua não, aqui tinha tudo, nem caminho tinha, usava a mata que você vai vê".

Existe uma sinergia que aflora as emoções quando eles falam sobre a Comunidade do Catu, há uma sensibilidade e respeito pelo local, um verdadeiro sentir-se em casa, cuidam, zelam e fazem questão de guiar os visitantes aos pontos mais bonitos do local. É uma verdadeira trilha guiada, sempre evidenciando os mais belos horizontes da mata. São pequenas aulas de campo com os conhecimentos populares e tradicionais. Expondo os afazeres diários desse povo com os costumes da caça, pesca, culinária e agricultura.

Essa situação representa um pouco a união da família ao lugar. Pronto para caminhar na Trilha? Sempre! O acontecimento da colheita do feijão verde não permitiu que alguns moradores participassem da trilha, porém, nos deram a motivação necessária, dizendo: "na próxima vamos fazer a trilha, pescar e caçar". Com a falta desses atores da Comunidade, outros moradores foram chegando ao grupo como foi o caso do Sr. João Chorão, Ladislau Neto e o outro João, pessoas conhecedoras da trilha e do lugar.

Saindo da casa do Sr. Chão, fomos seguindo o itinerário da trilha, onde de início percebe-se ao longo do Rio Catu várias plantações de hortaliças, prática muito difundida. Outra prática é a monocultura da cana-de- açúcar que cerca e avança por todo lado.

Os trilheiros, como iremos denominar os que se aventuram a fazer a trilha do 
Catu, não necessitam de muitos instrumentos para essa vivência. A maioria com roupas leves e simples, com chinelas nos pés e o outro com botas, mas o que chama atenção é a necessidade de seguir o caminho da trilha com um facão, instrumento cortante fundamental para aberturas, caso haja empecilhos (galhos e matos ralos).

A trilha do Catu, como prática social de uma comunidade é difícil de ser datada com propriedade, pela inexatidão do relato oral e a pouca produção escrita, por outro lado esse cenário constitui um espaço histórico fundamental. $\mathrm{Na}$ tentativa de contribuir com sua legitimação, o Instituto Federal de Educação, Ciência e Tecnologia do Rio Grande do Norte, Campus Canguaretama, no período de maio a dezembro de 2014, revitalizaram a trilha já existente. O projeto centrou nas questões relacionadas à educação ambiental e à valorização da cultura pelo fortalecimento da identidade e herança cultural da Comunidade Indígena do Catu, estando o projeto aprovado pelo Edital 01/2014 da Pró-Reitoria de Extensão - PROEX. Dessa maneira, percebe-se a relevante justificativa que o projeto assumiu para o desenvolvimento de atividades de cunho afirmativo, de manutenção, de conservação da diversidade e da identidade étnico-cultural da Comunidade do Catu.

Após conversas informais com o morador conhecido por "Chão" nos informou que as trilhas da Área de Proteção Ambiental (APA) serviam, anos atrás, para conduzir os parentes mortos, sendo conduzidos em redes de dormir, até o município de Espírito Santo/RN. Segundo as crenças, ao serem enterrados no cemitério ao lado da igreja, ficariam mais próximos do céu. Esse trajeto era realizado a pé, por homens, e de acordo como "chão" "durava em torno de 5 horas".

Na fala do mesmo morador, esse percurso (trilha) também era utilizado por ancestrais dos moradores para caçar, pescar e apanhar frutas, onde tornava-se os meios de sobrevivência. Em meio a esses relatos, ouvimos que seus filhos ainda hoje 
fazem uso da mata para caça e pesca. Um outro relato interessante é a presença de costumes vividos que passam de geração para geração dentro da mata do Catu. Um dos moradores diz alto que pegaram um "verdadeiro", na Comunidade a expressão verdadeiro está atrelada a captura do animal tatu.

Percebe-se nas relações moradores/natureza aproximações entre a trilha com a caça (sobrevivência), nesse arcabouço a trilha surgiu por necessidade de subsistência dos moradores. Diante das experiências citadas, a trilha permeia os modos de vida daquela comunidade, afirmando sua identidade cultural como povos tradicionais. Como espaço de lazer a vida na trilha é trajetória de conhecimento sensorial e cognitivo, em contexto cultural e lúdico nas descobertas e experiências sensoriais.

A trilha do Catu tem sentidos e significados próprios que mostram sua dinâmica cultural. A trilha é utilizada em práticas pedagógicas por professores e alunos de outras instituições que visitam a Comunidade em busca de intercâmbios culturais. Sendo usualmente potencializada para aulas de Educação Física de instituições visitantes.

Essa mesma trilha no contexto atual é lócus de vivências com a prática da caminhada, o corpo assume um sentido vivo dentro desse itinerário local, criando laços de comunicação entre o espaço e o meio ambiente, propiciando espaços de convivência humana com o corpo, a natureza e a cultura.

Essa vivência oportuniza e reconhece a importância que o meio ambiente tem em nossas vidas, além de testar os nossos limites, conhecer o nosso corpo, ver o quanto somos capazes através do movimento. Essas experiências, conectam aventura com conscientização, enfatizando a importância do meio ambiente ao mesmo tempo em que ele, com toda a sua beleza, no convida a entrelaçar conhecimentos ancestrais.

Ao longo da trilha do Catu foram implementadas pontes de madeira para 
facilitar o percurso dos trilheiros, o sr. João Chorão nos informou que "essa ação beneficiou muito a Comunidade". Os moradores do Catu informaram que a trilha possui um percurso de $10 \mathrm{~km}$, com período de duração de 03 à 04 horas dependendo do grupo, seu arcabouço natural é formado por vegetação tipicamente litorânea, com remanescentes de mata atlântica. A mata passa por processos de reflorestamento, sr. João afirma "você está vendo essa área? Está assim agora, era quase toda desmatada" frisou.

Com a intervenção e propostas de trabalho pelo Instituto Federal - IFRN do Campus Canguaretama e seus múltiplos colaboradores do projeto intitulado Sustentabilidade e identidade indígenas: um roteiro pelas trilhas do Catu, esse território vem sendo implementado com placas de sinalização, facilitando a caminhada orientada dos moradores e praticantes dessa trilha.

Essas sinalizações também embelezam o ambiente da prática, torna o lugar mais seguro para quem está conhecendo, são elementos que permitem uma aventura cultural na natureza com mais detalhes, pois, essas sinalizações com seus respectivos nomes traduzem um pouco da mata por onde caminha o trilheiro, fazendo o entrelaçamento das árvores, plantas e outros com o espaço natural, sendo mais um meio que propicia aprendizagens.

Nesse cenário, para que as trilhas tenham seu uso adequado, sofram o mínimo impacto e realize seu papel integrador, entre o visitante e o ambiente natural, a sinalização é fator primordial. Em muitas Unidades de Conservação e áreas de uso público os visitantes não contam com o auxílio de guias. No caso em referência, a comunidade do Catu, as placas servem como um dos meios de comunicação entre o visitante e a Comunidade, tendo em vista que para seu acesso a área, é interessante uma autorização entra as lideranças indígenas e os grupos. 
O caminhar na mata (trilha do Catu) proporciona trechos simples e outros mais complexos constituem a possibilidade de atender os desejos de várias faixas etárias. O simples, é como o caminhar em fragmentos mais planos e rígidos (solo), com poucos galhos de árvores e o andar sobre as pequenas pontes de madeira. O complexo, são as pequenas áreas alagadas em meio a vegetação rasteira, os aclives, pontos com galhos de árvores que dificultam a passagem e a utilização do equilíbrio corporal para poder caminhar por tronco de árvore em situações de pontos alagados. Apesar do contraponto, torna-se um ambiente especial que favorece a prática corporal de diversos grupos.

O local possibilita a criação de vários roteiros para vivências corporais, no entanto, percebe-se um distanciamento entre o poder público executivo quanto às políticas púbicas possíveis de serem desenvolvidas nesse lugar. Divulgação do lugar, georreferenciamentos e aproximações com turismo rural.

Em meio a essa diversidade de práticas corporais e dos recursos naturais, algumas e pequenas lagoas se apresentam no decorrer da trilha para encantar ainda mais o espaço. A lagoa da água fria é um local vivenciado por pequenos grupos que realizam além da trilha, usufruem realizando encontros e lanches em grupo.

Essa representação da paisagem natural para os moradores da Comunidade não se configura como a conhecida lagoa da água fria, mas os admiradores e visitantes costumam banhar-se nesse local. Existe uma sinalização em outro ponto como lagoa da água fria e que no imaginário dos moradores é a verdadeira,no entanto devido a água escura as pessoas estão evitando o banho. $\mathrm{O}$ banho vivenciado nesse pequeno espaço é muito frio e renova o sujeito. Após alguns quilômetros tornou-se um ambiente relaxante, revigorante e compensador.

O espaço ao redor encanta e nos faz intimamente ligados, sendo o meio que conecta e aflora o corpo a refletir sobre o contexto natural e nosso compromisso 
social com o cuidado ambiental e sustentável do local. Nesse sentido, um debate intersetorial com diversas instituições torna-se basal para o desenvolvimento da região e a preservação do meio ambiente.

\section{Um Esporte Apropriado pela Comunidade}

Nas andanças, um espaço chama atenção pela infraestrutura e organização, a primeira vista, percebe-se um espaço próprio para vivências corporais e esportivas de areia. A caixa de areia visualizada, torna-se um espaço facilitador para variados usos, com equipamentos esportivos ou não, podendo o corpo desenvolver práticas, como exemplo: O vôlei, o beach tênis, o frescobol, frisbee, slackline, futevôlei, corridas e outros. A partir disso, procuramos saber um pouco mais sobre a apropriação do espaço e do equipamento, dos esportes e seus praticantes, esse fenômeno emerge dos anseios do grupo, de acordo com Nascimento Júnior e Faustino (2009).

Ao empreende os relatos dos moradores produz sentidos, pertencimento e valorização a diversas culturas. Em contato inicial com o Cacique Luiz Katu, mencionamos a caixa de areia e de maneira breve, informou "para você saber mais, procure na Comunidade o parente Poty, ele é a pessoa mais apropriada que vai te dizer melhor". No dia posterior, encontramos o morador conhecido por Poty. O mesmo estava com amigos em uma pequena lanchonete jogando sinuca/bilhar. Nesse momento, conseguimos construir uma ponte com outros mradores, sendo recebidos e bem aceitos pelo grupo. Esses, possibilitaram diversas vivências das quais descreveremos a seguir.

$\mathrm{Na}$ lanchonete nos apresentamos e conseguimos uma maior aproximação com Poty, e em alguns minutos, fomos convidados a ir na sua residência. Chegando na sala da casa vimos diversos troféus, na maioria de eventos de futevôlei. Assim, começamos a conhecer Poty e o seu envolvimento com a Comunidade. 
Seu anseio pelo futevôlei inicia-se na Cidade de Canguaretama/RN, nas idas para a Escola como estudante do ensino básico. Na escola, foi gostando e criando laços com dois esportes (futebol e futevôlei), depois passou a frequentar um projeto social de futevôlei que contemplava aulas na cidade (Centro) e na Praia de Barra de Cunhaú. Com esses estímulos, Poty foi se apropriando de fundamentos do esporte (passe, domínio do corpo e outros) e mais tarde torna-se jogador profissional de futebol, tendo sua carreira percorrido alguns clubes, dos quais destaco seu último clube, o time Palmeiras da Cidade de Goianinha/RN.

Alguns anos atrás, conseguiu concursar e atualmente desenvolve trabalho como agente de saúde da Prefeitura de Canguaretama, sendo a Comunidade do Catu seu ambiente profissional. Poty, pessoa simples e que gosta muito da sua Comunidade, achando muito distante praticar o futevôlei no centro ou na praia da cidade com frequência, começou a mobilizar amigos que aceitaram a novidade e começaram a jogar em terra batida/barro duro, para melhorar pegaram uma carroça e trator e foram pegar areia próximo as plantações de cana de açúcar, melhorou, mesmo assim não foi suficiente para concluir a arena.

Depois buscou com os amigos, comerciantes, os setores e agentes públicos da Cidade de Canguaretama/RN os recursos financeiros ou materiais para iniciar o que configurou a caixa de areia. "Tinha tijolos que sobrou de uma construção da escola, falei com Luiz (diretor) e fui na prefeitura de Canguaretama pedir auxílio e a mesma autorizou a doação dos tijolos". Foi nesse contexto, ajudas diversas, tijolos, cimento e várias caçambas de areia que foi se tornado possível conseguir realizar o sonho.

Pretende-se mostrar como os moradores do lugar mantêm suas construções corporais identitárias. Sabê-las se torna importante para compreendermos o uso do corpo que eles fazem, cada qual a seu modo - quando da prática dos jogos modernos 
introduzidos ao longo dos tempos. Mauss (2003) indica-nos que fazer um inventário das técnicas corporais eficazes e tradicionais de uma sociedade, permite-nos consolidar certas especificidades de determinada cultura.

Com esse inventário, pode-se observar todo início como cita Poty que "os meninos não sabiam jogar quase nada, mas começaram a jogar (treinar) todos os dias, as vezes pela manhã e tarde e nos finais de semana". A rede era velha e a marcação da quadra também, mas depois conseguiram adquirir nova bola e rede especifica do esporte. Com o passar do tempo os moradores foram se apropriando do espaço e dos fundamentos do esporte.

O esporte, como visto na Comunidade e apropriado pelos frequentadores do lugar, tem convergências com as proposições de Santos e Dantas (2015, p. 43) quando explicam as relações entre o ser humano, o esporte, e a sociedade como "práxis humana que produz o sócio-histórico" em que é construída a partir do sentido atribuído nas realizações, é uma criação, uma significação instituída e inovadora.

Em meio a esse contexto, emergimos no contexto da prática, no intuito de sabera dinâmica, os modos de ser, as estruturas e especificidades da prática corporal instituída pela comunidade (STIGGER, 2002), o Futevôlei com toda sua organização e treinos. O esporte organizado por meios dos treinos na atualidade configura-se como esporte rendimento com objetivos de competições, e ao mesmo "tempo livre" de lazer no cotidiano Catu, vivido entre os sujeitos da Comunidade, posto que "as atividades desenvolvidas no tempo liberado do trabalho, ou no "tempo livre", não só das obrigações profissionais, mas também das familiares, sociais e religiosas. Apesar da polêmica sobre o conceito" (SILVA et al., 2011, p. 27), os autores anunciam que na atualidade e para os estudiosos do lazer, deve-se considerá-lo como tempo e atitude. 
No rendimento, percebe-se uma seriedade dos praticantes “joga sério, só quer brincar, dá de ombro, digo nada, se perder" (POTY, 2018). Uma outra possibilidade de levar o jogo a sério é, vamos apostar? Vimos duplas apostando em dinheiro, tornando o treino ainda mais competitivo. Isso é perceptível quase todos os dias, sendo a maneira deles. Enquanto isso, os jogadores que aguardam fo rado jogo ficam alimentando a rivalidade, "quer apostar mais, quero ver quandofo r nossa dupla" (POTY, 2018). Nesses jogos os atletas não perdem bola fácil, não deixa a bola cair.

Outros dias também percebemos o envolvimento de jogadores, com menor grau de habilidades específicas do esporte, onde o objetivo é jogar e fazer parte do grupo, aqui apropriado como esporte de lazer ou participação, de caráter lúdico e popular em que o grupo pode rediscutir organização e desenvolvimento que propiciam criatividade, transformação e possibilidades de reçaões sociais outras, e, ultrapassa a classificação que limita a compreensão do esporte na perspectiva do lazer e assume uma configuração complexa (STIGGER, 2002, p. 245) e singular pela identidade da Comunidade do Catu.

As vivências acontecem com duplas sempre diferentes, só permanecendo igual a dupla que vai ganhandoe convidando a próxima a entrar. As risadas fazem parte do cenário no jogo quando conseguem uma bela jogada. Os jogadores que assistem, fora do jogo, esperam e conversam sobre inúmeros acontecimentos diários: as festas, o dia-a- dia e outros encontros. Tornando um espaço social que contempla a convivênciae a socialização do grupo.

A partir do grande envolvimento da população jovem com o esporte futevôlei. Outra iniciativa de Poty foi criar copas de futevôlei durante o ano. As datas dos eventos estão intimamente entrelaçadas com comemorações dos povos dessa 
Comunidade. O dia 19 de abril tornou evidente no cenário brasileiro, o dia do índio, data essa que simboliza e tenta valorizar o índio do Brasil, data criada em 1943 pelo presidente Getúlio Vargas, com o Decreto Lei número 5.540. Desse modo, o evento se constitui em uma ação que envolve vários atores da Comunidade.

O evento do futevôlei tem duas edições e acontece em dois dias, sábado e domingo, caso o dia 19 de abril seja no sábado. Se não, realizam no final de semana posterior ao dia 19 de abril, não atrapalhando as atividades profissionais dos jogadores. Nessa mesma dinâmica nos dias de sábado e domingo, acontece todo ano, no dia 01 de novembro evento referente a comemoração da colheita da batata.

No sábado, a prática do esporte somente com os moradores, com o nível de dificuldade e de participação local. No domingo, o evento é aberto a várias duplas do Estado e de outros estados da federação, tornando-se um evento concorrido e de alto rendimento. Poty mantém amizades com atletas profissionais que participam de campeonato brasileiro favorecendo a vinda destes para prestigiar sua ação (evento), laços afetivos que transcorrem todas as edições dos eventos. As inscrições, convites e premiações para esse diaé fruto de planejamento anterior.

Os participantes vivenciam as competições ao mesmo tempo que contemplam o ambiente repleto do verde das plantações e as árvores que rodeiam o Rio Catu. Grande parte dos moradores da Comunidade estão assistindo e torcendo pelos atletas locais, mas, nem sempre os jogadores da Comunidade conseguem chegar a vitória, fato corriqueiro no esporte (ganhar e perder).

Os jogos do futevôlei, esporte apropriado pela Comunidade, nos é apresentado por jogadores de excelência, convidados e moradores do lugar. Esses atletas, conseguem controlar a técnica com eficiência, domínio de bola, antecipação ao que o adversário pretende realizar. Este esporte oferece a oportunidade de 
desenvolver habilidades corporais.

Em Kunz (1991) refletimos sobre a importância de se considerar a cultura de movimento e reconhecer suas significações e intencionalidades. Essas possibilidades e concretudes são realizadas por eventos na Comunidade, onde cito o evento intitulado "Copa Indígena de Futevôlei” criado por Poty tem duas edições no ano, no dia do índio e no dia da batata, são momentos que têm relação direta com seu povo e uma prática social inserida no âmbito do lazer se constituindo um estilo de vida (STIGGER, 2002) o estilo Catu de ser.

Nos eventos são disponibilizados aos atletas camisa, água, frutas, premiações (dinheiro e troféus). Os moradores prestigiam todos os lances, a infraestrutura também possui tendas montadas próximo a arena. Aliado a tudo isso o artesanato indígena é exposto e vendido como forma de divulgar, valorizar e trazer renda para a população. Fica evidenciado que o esporte futevôlei foi incorporado aos costumes dos moradores.

O começo, é o itinerário vivido das experiências teórico-práticas na escola indígena com a frase citada pelo morador do lugar, parafraseando uma expressão popular. Vando, como é mais conhecido, quando cita a expressão supracitada é para mostrar sua escolha como professor da Comunidade. Ele foi o primeiro professor da escola, em 1978/79, nesse período, Vando, estava saindo da $8^{\text {a }}$ série do fundamental, não existia ninguém para ensinar, então a pessoa que sabia "mais" era colocada para ensinar.

Entre as décadas de 1960 e 1980 surgiram movimento indígenas e de entidades indigenistas em quase todas as regiões brasileiras, decorrentes da necessidade interna de se mobilizarem contra as diversas situações de violência. Paralelamente a isso, a sociedade brasileira também se organizava contra aditadura 
militar, propondo novos modelos políticos e econômicos com bases democráticas. Só com a redemocratização do Brasil o indígena foi reconhecido como cidadão de direitos.

Dentre as legislações, podemos citar, em âmbito nacional, a Constituição Federativa do Brasil de 1988 e a Lei de Diretrizes e Bases da Educação Nacional 9394/96, visto que reconhecem aos indígenas o direito cultural como povos tradicionais. Estas legislações garantem o direito aos povos indígenas a uma escola com características específicas que atendam às realidades e às necessidades de cada povo.

Dessa maneira, a Escola Municipal Indígena, situada no Sítio Catu dos Eleotérios, integra ao Sistema Municipal de Educação da Cidade de Canguaretama/RN. A modalidade oferecida é tratada de acordo com a legislação específica e as Diretrizes Curriculares inerentes. Os significativos avanços no que se refere à Educação Escolar indígena são frutos do movimento social organizado, da articulação e mobilização de indígenas e indigenistas para a elaboração de propostas, intervenções e acompanhamento dos processos legislativos.

A escola é composta por diretor, professores indígenas e comunidade escolar. A partir dos processos históricos e a realidade da Comunidade torna possível enxergar os povos indígenas atuais. As memórias sociais e os fatos relevantes que anunciam uma trajetória de resistência e de sobrevivência indígena em território potiguar.

A escola, apresenta as características garantidas na resolução citada anteriormente. Uma escola com infraestrutura simples, ao mesmo tempo que recebe equipamentos modernos de tecnologia, antenas de servidores de internet, mas que no dia-a-dia é pouco efetivada na prática, por falta ou inexistência de manutenção. Os 
dados da internet, em vários momentos, ficam incompatíveis para acesso aos computadores da escola. Nesse caminho, para os moradores da Comunidade a escola tem que ser diferenciada a partir da merenda escolar e do ensino, com comidas da tradição indígena e a língua tupi antigo.

\section{Foto 1: Dança do Toré}

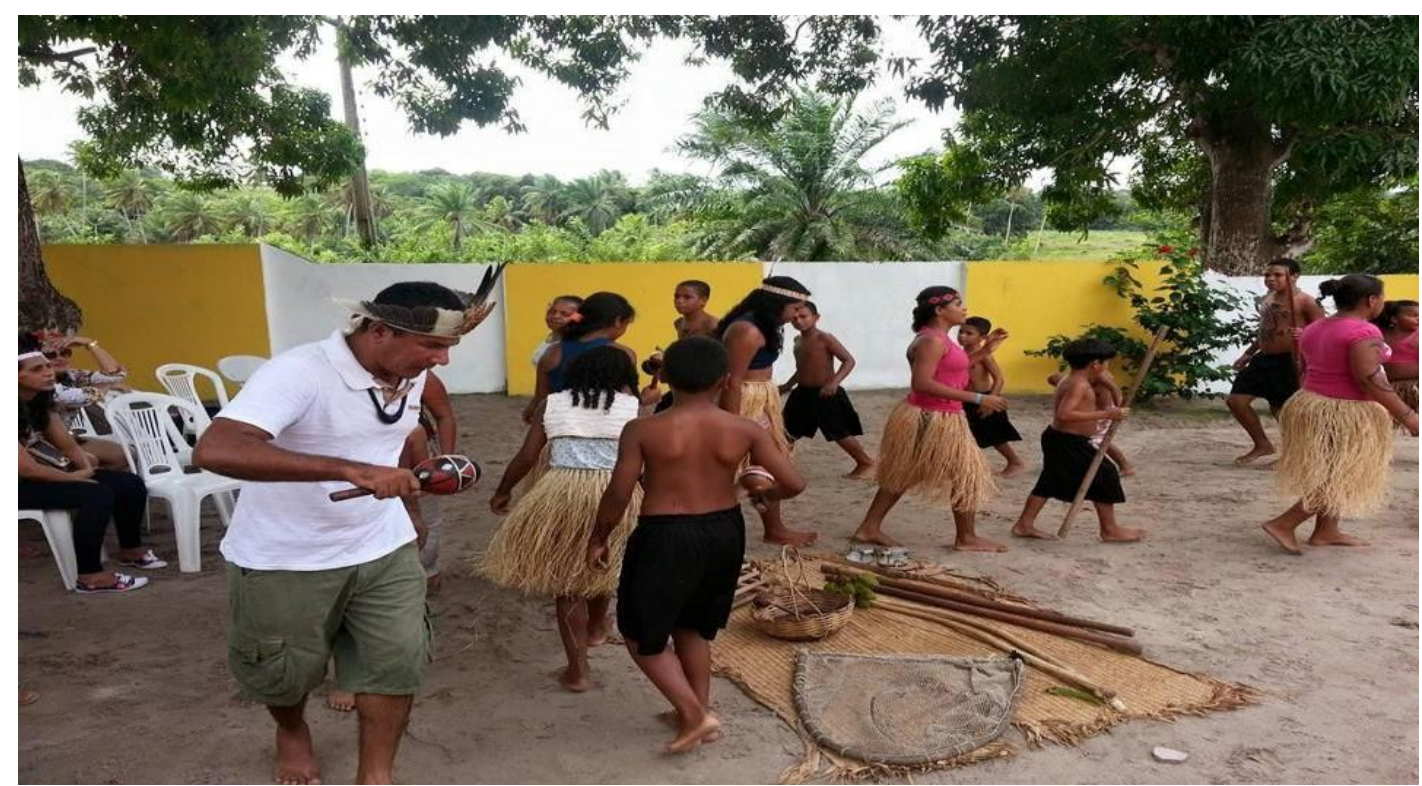

Fonte: Pesquisa de campo, 2016.

O toré da escola é uma manifestação simbólica da identidade e cultura dos povos dessa Comunidade. Ocorre em diversos momentos da escola, especificamente, no contra turno escolar, onde é ofertada a parte diversificada do currículo. Outros momentos da dança do Toré acontecem nas apresentações para grupos, visitantes, escolas, pesquisadores e eventos da Comunidade. É composto de musicalidade, dança, ornamentos, canto e envolvimento. Em Daolio (1995) podemos compreender as relações que o corpo faz com os elementos específicos da sua cultura.

A vivência da Dança do Toré na escola faz entrelaçamentos com o Projeto Político Pedagógico (PPP), sendo este, o instrumento que possibilita que a comunidade indígena expresse qual escola deseja, de que forma a escola deve atender aos seus interesses, como ela deve ser estruturada, e como se integra à vida e aos 
projetos comunitários. A construção desse documento configura as bases para a edificação da identidade da escola.

Outros cenários estão postos e configuram as realizações na escola, esse entrelaçamento permite vivências corporais na e para a educação indígena, de acordo com Mauss (2003) as sociedades vão se apropriando dos seus corpos a maneira que vão construindo hábitos e práticas corporais.

As vivências com o Arco e Flecha na escola indígena fazem parte dos conteúdos do componente curricular de etno-história, ministrada pelo professor e indígena da Comunidade do Catu, onde aborda de maneira transdisciplinar a história dos povos indígenas e suas relações com práticas ancestrais e atuais.

As vivências percebidas nas aulas de etno-história são plurais e estão ligadas a diversidade sociocultural das populações indígenas local, regional e Nacional. Conferindo reivindicações das comunidades indígenas permeadas pela história e cultura. Os diversos conteúdos têm como intuito conferir ações práticas que dialoguem com as questões históricas e contemporâneas das comunidades indígenas de maneira multidisciplinar.

O contexto dessas práticas educacionais, sempre tem motivado o desenvolvimento de suas especificidades, criando as representatividades do grupo e da comunidade. Nesse sentido, Serres (2004) nos faz compreender um movimento dialógico entre as brincadeiras e as várias formas de ensinamentos e apropriações que a comunidade apreende para construir suas subjetividades.

As vivências da Cultura de Movimento da Escola Indígena acontecem dentro da escola, no próprio pátio. Nesse local, são desenvolvidas a maioria das brincadeiras dos alunos, é o local de pura diversão. Percebe-se uma infraestrutura escolar carente, necessitando de reparos, manutenção. Mesmo assim, o corpo vai construindo sentidos e 
significados, com a cultura local.

As particularidades e organização com os conteúdos desenvolvidos pelos professores indígenas da Comunidade estão articuladas com as orientações do documento analisado, o (PPP) da escola, contempla os princípios da educação indígena pautando-se numa proposta intercultural, comunitária, multilíngue, diferenciada, com o foco nos saberes tradicionais do povo Catu (Etnia Potiguara). Obedecendo assim a um calendário específico, dando acesso aos conhecimentos nacional.

Quadro 02: Práticas Corporais da Escola Indígena João Lino da Silva

\begin{tabular}{|c|c|c|}
\hline $\begin{array}{l}\text { JOGOS, BRINQUEDOS, } \\
\text { BRINCADEIRAS E } \\
\text { DANÇAS }\end{array}$ & MATERIAIS & EXECUÇÃO \\
\hline Peteca & $\begin{array}{cccc}\text { Tradicional } & - & \text { Palha } & \text { demilho. } \\
\text { Material } & \begin{array}{c}\text { sintético } \\
\text { visitantes. }\end{array} & - & \text { para }\end{array}$ & $\begin{array}{c}2 \text { ou mais participantes. } \\
\text { Princípio: } \begin{array}{c}\text { Não } \\
\text { deixar }\end{array} \\
\text { peteca cair. }\end{array}$ \\
\hline Arco e Flecha & $\begin{array}{c}\text { Arco tradicional: pau dearco, } \\
\text { embiriba/imbiriba; cordão decisal. Flecha: } \\
\text { madeiraTapoca. }\end{array}$ & $\begin{array}{l}\text { Atirar no alvo (desenho do } \\
\text { peixe), tem numeração } 01 \text { a } \\
\text { 10. Quem acerta no olho do } \\
\text { peixe tem a maior pontuação. }\end{array}$ \\
\hline Pega o coelho & Roda Humana & $\begin{array}{c}\text { Grande roda de crianças: ao } \\
\text { centro 01 criança (coelho). } \\
\text { Por fora da roda outracriança } \\
\text { (caçador). }\end{array}$ \\
\hline Peão/carapeta & Cordão $\begin{array}{ll}\text { fino, linha } \\
\text { e catemba de coco. }\end{array}$ & $\begin{array}{l}\text { Jogo individual, utilizando as } \\
\text { duas mãos na intenção de } \\
\text { movimentar o pião. }\end{array}$ \\
\hline Zarabatana & $\begin{array}{c}\text { Madeira tapoca para o tubo ebambu para o } \\
\text { dardo. }\end{array}$ & $\begin{array}{c}\text { Brinquedo de sopro } \\
\text { desenvolvido na intenção de } \\
\text { lançar o dardo em um alvo } \\
\text { estático ou não. }\end{array}$ \\
\hline Jogo da Castanha & Várias castanhas de caju & $\begin{array}{c}\text { Faz um buraco (panela) no } \\
\text { chão, os brincantes ficam a } \\
\text { uma distância aproximada de } \\
5 \text { metros para arremessar as } \\
\text { castanhas. }\end{array}$ \\
\hline Jogo da Melancia & Várias crianças & $\begin{array}{l}\text { As crianças tendam pegar a } \\
\text { melancia, mas o cachorro } \\
\text { tentará impedir. }\end{array}$ \\
\hline
\end{tabular}




\begin{tabular}{|c|c|c|c|}
\hline Toré & Representação $\quad \begin{array}{c}\text { simbólica.Grande } \\
\text { círculo, em roda } \\
\text { humana. }\end{array}$ & $\begin{array}{c}\text { Dança circular com ritmos } \\
\text { marcado pelo pé e e } \\
\text { instrumento da maraca. }\end{array}$ \\
\hline
\end{tabular}

Fonte: Pesquisa de campo, 2016.

As práticas identificadas fazem parte de uma dinâmica particular da escola, em alguns momentos essas práticas fazem parte da oralidade da Comunidade, e outras vivenciadas na escola. Quando participamos em alguns momentos no turno matutino, onde acontecem as aulas do currículo proposto pela Lei de Diretrizes e Bases da Educação Nacional e Diretrizes Curriculares Nacional, nos envolvemos em vários momentos no diurno, com mais tenacidade, por ser a parte do currículo diferenciado, onde percebe-se uma maneira metodológica diferenciada, em que ocorrem a efervescência dos jogos e brincadeiras.

\section{Foto 2: Peteca Tradicional (Palha de Milho)}

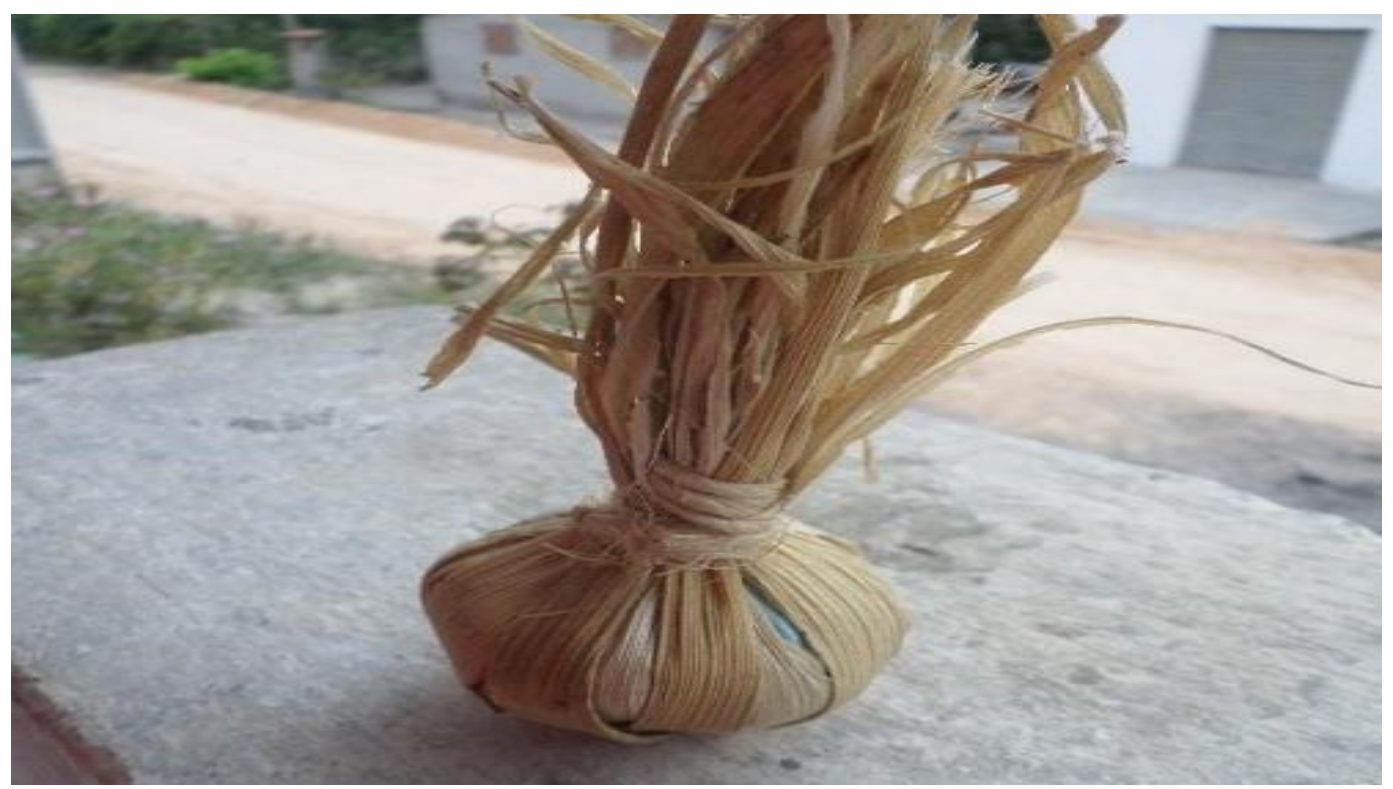

Fonte: Dados da Pesquisa de campo, 2016.

Assim as brincadeiras no dia-a-dia da escola acontecem mais no período da tarde, já que a escola é de tempo integral. A organização curricular da escola está estruturada pela educação integral aos seus alunos, pela manhã das 07:00 às 11:15 (intervalo para almoço) e a tarde das 13:00 às 16:00.

Essas aulas decorrem, do início ao fim, com a professora estimulando e 
trabalhando com o tronco Tupi antigo, sempre relacionando os significados do Tupi com o português. Todos os servidores e alunos têm seu nome em tupi antigo dando sentido, significado e pertencimento étnico a essa população.

No momento da chamada para saber a presença dos alunos a professora utiliza o nome dos alunos em tupi e a forma de responder é reproduzir seu nome com a tradução/significado em português. Ex: Professora: YBYTU? Aluno: VENTO! Outra dinâmica acontece com a oração do pai nosso, os trechos/estrofes são falados pela professora em tupi, os alunos repetem, na sequência a professora fala a tradução/significado e os alunos vão repetindo.

Momento da aula com os conteúdos do Tupi antigo, objetivando o desenvolvimento dos alunos com as especificidades da Etnia Potiguara. O Tupi antigo estimulado nas aulas garante o acesso à língua indígena, considerada como um patrimônio.

A identificação das dinâmicas culturais na Escola Indígena e toda sua singularidade estimula uma concepção de Educação intercultural, atendendo as demandas da Comunidade. Assim, as aulas vêm lançando os conhecimentos na perspectiva do multiculturalismo aberto e interativo com troca de saberes, e interações com outras populações indígenas do Brasil.

Aulas com a compreensão da diversidade cultural que para Candau "acentua a interculturalidade, por considerá-la a maisadequada para a construção de sociedades democráticas que articulem políticasde igualdade com políticas de identidade e reconhecimento dos diferentes grupos culturais" (2012, p. 243). Observa-se nas aulas do currículo diferenciado, no contra turno escolar, exercícios de empoderamento dos alunos na construção da sociedade, na perspectiva intercutural. 


\section{Fim da Trilha, Início de Outros Caminhos}

Consideramos que a construção desse conhecimento e as análises metodológicas ao longo do trabalho, e todo processo teórico/prático, documental, foi sentido e vivido. A Escola deve apropriar-se dos saberes e efetivar o currículo, fato que para os sujeitos e uma comunidade escolar, somente o que faz sentido e tem significado ao grupo se torna conhecimento aplicável na vida coletiva e em diálogo com a cultura local.

Por estar localizada na zona rural do Município de Canguaretama, a Comunidade do Catu tem um grande potencial para subsidiar as práticas corporais como objrto de conhecimento da Educação Física na Escola e como atividade da Comunidade, o que poderá fomentar conteúdos múltiplos, relacionando a Educação Física com a Educação étnico racial na escola. A Comunidade do Catu pode ampliar caminhos que concorrem para uma educação integral da criança e dos adolescentes indígenas em harmonia com os saberes dos velhos e de ações resultantes do diálogo, respeito e garantia de direitos que se interdependem em ideias, ações, vontades (políticas e econômicas) e sobretudo, do olhar sensível e ressignificado para as populações indígenas.

\section{REFERÊNCIAS}

BRASIL. Constituição (1988). Constituição da República Federativa do Brasil. Brasília, DF: Senado Federal: Centro Gráfico, 1988.

BRASIL. Lei de Diretrizes e Bases da Educação Nacional, Lei número 9394, 20 de dezembro de 1996.

CANDAU, Vera Maria Ferrão. Diferenças culturais, interculturalidade, e educação em direitos humanos. Educ. Soc., Campinas, v. 33, n. 118, p. 235- 250, jan.-mar. 2012.

DAOLIO, Josimar. Os significados do corpo na cultura e as implicações para a Educação Física. Revista Movimento. Ano 2, n.2, 1995.

KUNZ, E. Educação Física: ensino e mudanças. Ijuí: Unijuí, 1991. 
LUCIANO, G. dos S. O Índio brasileiro: o que você precisa saber sobre os povos indígenas no Brasil de hoje. Coleção Educação Para Todos. Série Vias dos Saberes, volume 1. Brasília: Ministério de Educação Continuada, Alfabetização e Diversidade; Rio: LACED/Museu Nacional, 2006. ISBN 85-98171-57-3. Disponível em: http://unesdoc.unesco.org/images/0015/001545/154565por.pdf. Acesso em 26 set.2018.

MATOS, Lucília. Belém: do direito ao lazer ao direito à cidade. In: MARCELLINO, Nelson Carvalho (org.). Lazer e Esporte: políticas públicas. 2. ed. Campinas: Autores Associados, 2001.

MAUSS, Marcel. Sociologia e antropologia. Tradução de Paulo Neves. São Paulo: Cosac e Naify, 2003.

NASCIMENTO JÚNIOR, José Roberto do; FAUSTINO, Rosângela Célia. Jogos indígenas: o futebol como esporte tradicional Kaingang. Pensar a Prática, v.12, n.3, p. 1-12, set.dez., 2009.

RIO GRANDE DO NORTE. Projeto RN Sustentável. Manual Operativo, 2013. Disponível em http://www.rnsustentavel.rn.gov.br/smiv3/site/documentos/arquivo/193205ab6f34b19e6 2e7a7b87d3b5fa6.pdf. Acesso em 03 março 2018.

SANTOS, Antônio de Pádua de; DANTAS, Maria Isabel. Esporte e Cultura: relações possíveis? In: Copa do mundo 2014: debates sobre mídia e cultura Natal: EDUUFRN, 2015.

SILVA, Débora; STOPPA, Edmur; ISAYAMA, Helder; MARCELLINO, Nelson; MELO, Victor. Importância da recreação e do lazer. Brasília: Gráfica e Editora Ideal, 2011.

SERRES, Michel. Variações sobre o corpo. Rio de Janeiro: Bertrand, 2004.

STIGGER, Marco Paulo. Esporte, lazer e estilos de vida: um estudo etnográfico. Campinas: Autores Associados, 2002.

\section{Endereço dos/as Autores/as:}

Carlos Gomes de Medeiros Neto

Endereço Eletrônico: carlosesporteelazer@yahoo.com

José Pereira de Melo

Endereço Eletrônico: jose.melo@ufrn.br

Marta Genú Soares

Endereço Eletrônico: martagenu@gmail.com 